\title{
An evaluation of open scalp wounds
}

\author{
G. M. FULLARTON, ${ }^{1}$ C. J. MACEWEN,${ }^{1}$ R. MACMILLAN ${ }^{2} \&$ \\ I. J. SWANN ${ }^{1}$
}

Department of ${ }^{1}$ Accident and Emergency, Glasgow Royal Infirmary, and ${ }^{2}$ Department of Neurosurgery, Southern General Hospital, Glasgow, Scotland

\section{SUMMARY}

A retrospective study of 661 adult patients with open scalp wounds attending the Accident and Emergency Department of Glasgow Royal Infirmary, Glasgow, Scotland, was performed. Detailed information was recorded about history, nature of open wounds ('contused' or 'incised'), wound exploration and radiological findings.

The commonest cause of injury was assault $(40 \%)$, followed by falls $(34 \%)$. Half of the patients had been drinking alcohol: The majority of scalp wounds were 'contused' $(84 \%)$ resulting equally from assaults and falls; 'incised' wounds $(16 \%)$ were more commonly due to assault. Although division of the occipitofrontalis aponeurosis was infrequent $(18 \%)$, most $(78 \%)$ of the skull fractures occurred in this group. Wound exploration detected nine fractures not evident on skull X-rays.

To maximise fracture detection rate, careful wound exploration should be an important adjunct to skull radiography and, in particular, division of the occipitofrontalis aponeurosis should alert the casualty officer to the likelihood of a skull fracture.

\section{INTRODUCTION}

Half of all adults who attend accident and emergency (A\&E) departments in Scotland with head injuries have scalp wounds (Jennett et al., 1977; Strang et al., 1978). It is important to determine from this large pool of patients those with underlying skull fractures, as those with compound fractures are at risk of intracranial infection and haematoma formation, but these fractures may not be clinically obvious as they often present to the casualty officer without neurological symptoms or signs (Strang et al., 1978; Swann et al., 1982; Jennett \& Miller, 1972).

Wound exploration and skull radiography have been advocated as aids to diagnosis (Jennett \& Miller, 1972; Mendelow et al., 1983) but their value in detecting skull fractures in patients with particular types of scalp wound has not been reported. 


\section{METHOD}

The medical records of patients who had attended the A\&E Department of Glasgow Royal Infirmary during a period of 6 months were studied retrospectively. Those $\stackrel{\circ}{\rightarrow}$ patients older than 12 years, with a diagnosis of an open scalp wound, i.e. a wound in which the full thickness of skin between the eyebrows and occiput is breached, were selected and alternate medical records were examined. Wounds were categorised as $\underline{3}$

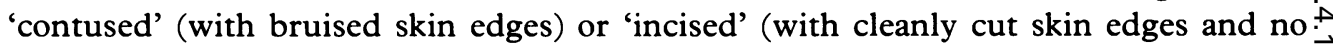
bruising). The study did not include minor abrasions or grazes, and almost all wounds required suturing.

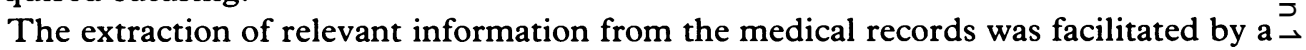
stylised method of documentation (Fig. 1). The information obtained also included $\underset{9}{3}$ history, neurological findings and radiology reports. Casualty officers had been advised to $\frac{\widehat{\widehat{S}}}{\mathcal{T}}$ explore wounds under local anaesthesia, with a good light, using a sterile gloved finger $\vec{\oplus}$ to feel for a fracture. If there was doubt about what was felt or seen, then a West's Sedf $\stackrel{\infty}{\infty}$ retaining retractor was sometimes used but the wound was not enlarged. If doubt st remained, a more experienced member of staff examined the wound to confirm or der. the presence of a fracture.

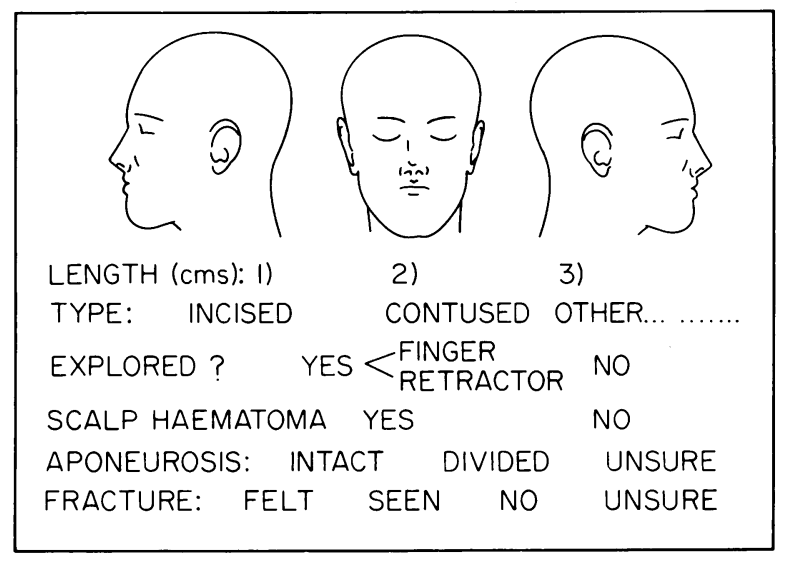

Fig. 1 Method of documentation. 


\section{RESULTS}

Six hundred and sixty-one patients were included in the study, $74 \%$ male and $26 \%$ female. The age distribution was 13-96, with a mean age of 39 years. More than half of the patients $(54 \%)$ presented between $6.00 \mathrm{pm}$ and $2.00 \mathrm{am}$. The commonest cause of injury was assault $(40 \%)$, with falls second $(34 \%)$, the remainder being divided between work, road traffic accidents (RTA) and sports injuries (Table 1). Half of the patients had been drinking alcohol.

Each patient was classified on the Glasgow Coma Scale (Teasdale \& Jennett, 1974) at the time of presentation. Five hundred and eighty-four patients $(88 \%)$ had maximum scores of 15 (eyes open spontaneously, no motor or verbal deficit); 51 patients $(8 \%$ ) scored 14 on the Coma scale, whilst only 22 patients (3\%) had a score of 13 or less. Skull $\mathrm{X}$-rays were obtained in 581 patients $(88 \%)$.

Table 1 Cause of injury

\begin{tabular}{lrc}
\hline Cause & $n$ & Percentage \\
\hline Assault & 264 & 39.9 \\
Fall & 222 & 33.6 \\
RTA & 55 & $8 \cdot 3$ \\
Work & 36 & $5 \cdot 4$ \\
Sport & 18 & $2 \cdot 7$ \\
Other & 43 & $2 \cdot 5$ \\
Not Recorded & 23 & 3.5 \\
Total & 661 & 100 \\
\hline
\end{tabular}

Features of wounds

Most of the wounds were linear (74\%) and most patients had a single wound (86\%). The most frequent site was in the frontal region $(45 \%)$ and only $4 \%$ were in the temporal region (Table 2). Almost half of the wounds $(47 \%)$ were less than $3 \mathrm{~cm}$ in length, only $17 \%$ were over $5 \mathrm{~cm}$.

Table 2 Site of laceration

\begin{tabular}{lcc}
\hline Site & $n$ & Percentage \\
\hline Frontal & 295 & $44 \cdot 6$ \\
Parietal & 188 & $28 \cdot 6$ \\
Occipital & 131 & $19 \cdot 8$ \\
Temporal & 23 & $3 \cdot 5$ \\
Not Recorded & 24 & 3.6 \\
Total & 661 & 100 \\
\hline
\end{tabular}


Examination of the wounds revealed that $556(84 \%)$ were 'contused', $80(12 \%)$ were 'incised' and in $25(4 \%)$ the type was not specified.

Incised wounds $(>5 \mathrm{~cm})$ were more likely to be due to assault $\left(68 \%\right.$ of cases) but $\frac{3}{\Phi}$ contused wounds $(>5 \mathrm{~cm})$ were equally likely to be due to a fall or assault.

\section{Wound exploration and fracture detection}

In 390 cases ( $59 \%$ ), wound exploration was performed, the nature of the skin edges, the $\frac{\frac{\bar{\sigma}}{\bar{D}}}{\overline{\frac{D}{}}}$ state of the occipitofrontalis aponeurosis and the presence of a fracture were noted. Three quarters of wounds greater than $3 \mathrm{~cm}(79 \%)$ were explored, but this was carried के out in only one third $(37 \%)$ of the smaller wounds. The nature of the laceration. (contused or incised) did not affect the rate of exploration. The aponeurosis was divided $\vec{\omega}$ in $69(18 \%)$ of the wounds explored and this rate was similar for both contused and $\stackrel{\odot}{\Phi}$ incised wounds.

Casualty officers interpreted the radiographs of 10 patients as showing skull fractures.: Subsequently, three were reported as being normal X-rays, one was discovered to be an: old fracture and one had a petrous temporal fracture with an unrelated small occipital $\vec{\circ}$

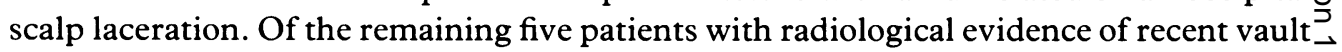
fracture, details of wound exploration were recorded in four. There were $362(55 \%) 3$ patients who had both skull X-ray and wound exploration. Skull fracture was detected⿳亠丷厂犬 in 13 of these (Table 3).

Table 3 Patients X-rayed and wounds explored $(n=362)$

\begin{tabular}{lcc}
\hline & \multicolumn{2}{c}{ Wound exploration } \\
\cline { 2 - 3 } Skull radiography & Fracture & No fracture \\
\hline Fracture & 2 & 2 \\
No fracture & 9 & 349 \\
\hline
\end{tabular}

Nine of the eleven fractures detected on wound exploration were not evident on skul $\mathrm{X}$-ray, and in three of these fractures were both felt and seen. Only two of the fourt: fractures evident on X-ray were detected on wound exploration (one linear and on $e^{3}$. depressed).

Only in wounds greater than $2 \mathrm{~cm}$ in length were fractures definitely detected by exploration. Of the 69 patients in whom the aponeurosis was divided, $11(16 \%)$ had 2 ? palpable skill fracture, only two of which were evident on radiography, whereas onlyo two $(0.6 \%)$ of patients with an intact aponeurosis had an associated skull fracture on radiography and no fractures were detected on wound exploration.

\section{DISCUSSION}

An important role of the accident and emergency department in the management of the patient with a minor head injury is the early recognition of those with an increased risk 
of intracranial haematoma and infective complications of skull fractures. A recent study (Mendelow et al., 1983) has suggested that two particular features, namely conscious level and the presence of a skull fracture are important in detecting those patients at most risk of developing traumatic intracranial haematomata, i.e. altered conscious state and skull fractures: 1 in 4 risk of haematoma. The presence of a skull fracture alone indicates a risk of 1 in 32 of developing a haematoma. Any clinical features which may help identify or exclude a skull fracture are, therefore, of importance in determining the need for observation and antibiotic therapy.

In this study, $88 \%$ of patients were fully conscious on presentation (Glasgow Coma Scale: 15; Teasdale \& Jennett, 1974), although almost half of these (275) had been drinking alcohol. This is not a group about which to be complacent as nine $(3 \cdot 3 \%)$ had a compound skull fracture. A high index of suspicion of a penetrating skull injury is necessary in such patients (Jennett \& Miller, 1972). However, it is even more important to determine the presence of a skull fracture in those whose conscious level is depressed. This group who most often present at night, apparently under the influence of alcohol, may prove uncooperative and obtaining good quality skull $\mathrm{X}$-rays can be difficult (Swann et al., 1982).

From this work, it is clear that the vast majority of open scalp wounds are of the contused type due to blunt trauma and this is related to the predominant causes of injury: assaults and falls under the influence of alcohol. Contused lacerations of any length were equally likely to be due to a fall as assault. A long incised wound was more likely to be due to assault than a fall.

The length of an open wound rather than the nature of its edges determines the ability to adequately explore it. It is clear that wound exploration is less easy in the smaller wounds and skull radiography is necessary to exclude a fracture. In the larger wounds which allow adequate exploration, the presence of a divided aponeurosis should alert the casualty officer to the likelihood of a skull fracture.

Nine fractures detected on wound exploration were not evident on skull radiographs. In some cases, there was a fracture of the outer table of the skull which is difficult to detect on radiography (tangential views may help). Alternatively, a proportion of our fractures detectable only on wound exploration may simply be clinical misinterpretation. In other cases, however, clinically significant fractures may be missed on poor quality X-rays. Follow up X-rays may be useful in this group of patients to confirm the presence of a fracture. The detection of skull fractures in radiologically negative patients at operation or post mortem has been described before (McKissock et al., 1960). This may represent a proportion of those patients with negative radiology who subsequently develop intracranial haematomas (Galbraith \& Smith, 1976).

Exploration of scalp lacerations is an important adjunct to skull radiography and, in order to maximise fracture detection rate, it should be carried out whenever possible.

\section{REFERENCES}

Galbraith S. \& Smith J. (1976) Acute traumatic intracranial haematoma without skull fracture. Lancet ii, 501-2. 
Jennett B. \& Miller J. D. (1972) Infection after depressed fracture of skull. Implications for management o\$ non-missile injuries. Fournal of Neurosurgery 36, 333-9.

Jennett B., Murray A., MacMillan R., McFarlane J., Bentley C. \& Hawthorne V. (1977) Scottish head injur management study. Head injuries in Scottish Hospitals. Lancet ii, 696-8.

McKissock W., Taylor J. C., Bloom W. H. \& Till K. (1960) Extradural haematoma-observations on 125. cases. Lancet ii 167-72.

Mendelow A. D., Teasdale G., Jennett B., Bryden J., Hessett C. \& Murray G. (1983) Risk of intracrania' haematoma in head injured patients. British Medical fournal 287, 1173-6.

Strang I., MacMillan R. \& Jennett B. (1978) Head injuries in accident and emergency departments at Scottislä Hospitals. Injury 10, 154-9.

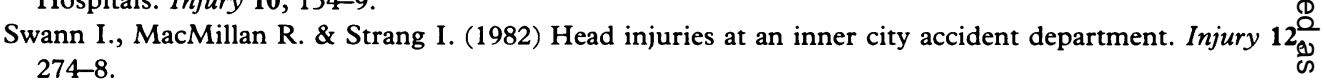

Teasdale G. \& Jennett B. (1974) Assessment of coma and impaired consciousness-a practical scale. Lancet iip $81-4$.

Received 10 August 1986; accepted 10 November 1986 